\title{
SENTIMEN ANALISIS TWEET PORNOGRAFI KAUM HOMOSEKSUAL INDONESIA DI TWITTER DENGAN NAIVE BAYES
}

\author{
Andre Maureen Pudjajana \\ Fakultas Teknologi Informasi, Program Studi Magister Sistem Informasi \\ Universitas Kristen Satya Wacana \\ Email: 972016024@student.uksw.edu \\ Danny Manongga \\ Fakultas Teknologi Informasi \\ Universitas Kristen Satya Wacana \\ Email: dmanongga@gmail.com
}

\begin{abstract}
ABSTRAK
Media sosial adalah salah satu media yang menghubungkan orang-orang diseluruh dunia. Namun media sosial juga menjadi sarana untuk penyebaran hal-hal negatif seperti pornografi. Berita pornografi yang mendapat banyak perhatian ditahun 2017 yaitu pornografi pada kaum homoseksual yang melakukan pesta seks di beberapa kota di Indonesia. Kehadiran para kaum homoseksual dilarang di Indonesia dan mendapat diskriminasi dari masyarakat. Penolakan yang dialami membuat kaum homoseksual membuat kaum tersebut menggunakan media sosial seperti Twitter untuk membuka diri di khalayak umum, mencari pasangan sejenis, dan mencari penghasilan. Penelitian ini dilakukan sentimen analisis pada tweet Twitter sebagai text mining menggunakan metode Naïve Bayes. Tujuan penelitian ini adalah mengetahui hasil sentimen positif dan negatif terhadap data uji tweet dan berdasarkan hasil pengujian tersebut dapat disampaikan kepada pengguna Twitter secara luas untuk menggunakan Twitter secara tepat. Selain itu juga, perhitungan Naive Bayes dibandingkan dengan k-Nearest Neighbor (k-NN) untuk mengetahui tingkat akurasi. Hasil sentimen analisis terhadap 500 data uji menunjukkan bahwa nilai sentimen negatif sangat tinggi yaitu $68.4 \%$. Sedangkan hasil perbandingan akurasi kedua metode adalah metode Naïve Bayes sebesar $87.48 \%$ dan k-NN 85.40\% dimana metode Naïve Bayes lebih akurasi dibanding metode kNN.
\end{abstract}

Kata kunci: twitter, sentimen analisis, homoseksual, naïve bayes, k-NN.

\begin{abstract}
Social media is one of media that connects people around the world. However, social media is also a media for the spread of negative things such as pornography. The pornography news that gets a lot of attention in 2017 is homosexuals pornography who have sex parties in several cities in Indonesia. The presence of homosexuals is prohibited in Indonesia and discriminated against by the public. The rejection experienced by homosexuals make them using social media such as Twitter to open up in the general public, looking for similar partners, and earn income. In this research, conducted sentiment analysis on Twitter tweet as text mining using Naive Bayes. The purpose of this research is to know the results of positive and negative sentiments to the test data tweets and based on the test results can be submitted to Twitter users widely to use Twitter appropriately. In addition, the calculation of Naive Bayes compared with $k$-Nearest Neighbor $(k-N N)$ to determine the level of accuracy. Result of sentiment analysis to 500 test data indicate that the value of negative sentiment is very high that is $68.4 \%$. While the result of comparison of both method accuracy is Nä̈ve Bayes method equal to $87.48 \%$ and $k$-NN $85.40 \%$ where Nä̈ve Bayes method more accuracy than k-NN method.
\end{abstract}

Keywords: twitter, sentiment analysis, homosexual, nä̈ve bayes, $k-N N$.

\section{PENDAHULUAN}

Kemajuan era globalisasi saat ini telah memberi dampak positif dan negatif diberbagai bidang kehidupan. Salah satu bidang tersebut adalah kemajuan teknologi informasi yang membantu dan mempermudah manusia. Namun kemajuan teknologi juga memberi banyak dampak negatif yang merugikan. Media sosial merupakan contoh kemajuan teknologi informasi pada saat ini dan menarik perhatian banyak orang. Contoh media sosial yang umumnya digunakan yaitu Facebook, Twitter, 
Instagram, dan Path. Media sosial menjadi salah satu media yang menghubungkan orang-orang di seluruh dunia. Namun kehadiran media sosial juga menjadi salah satu sarana untuk terjadinya hal-hal negatif yang merugikan seperti penyebaran status, gambar, dan video pornografi.

Berita dalam negeri tentang pornografi yang menarik perhatian banyak pihak di tahun 2017 yaitu pornografi pada kaum homoseksual (kaum gay) yang melakukan pesta seks. Beberapa berita tersebut diantaranya yaitu pesta seks di salah satu ruko Kelapa Gading, Jakarta Utara [1], pesta seks di tempat sauna Harmoni, Jakarta Pusat [2], dan pesta seks di Hotel Oval, Surabaya [3]. Kaum homoseksual adalah kaum laki-laki yang menyukai sesama laki-laki, menjalani hubungan sebagai pasangan, atau telah melakukan hubungan seksual [4]. Indonesia adalah negera hukum yang tidak melegalkan atau melarang hubungan sesama jenis. Selain hukum, masyarakat Indonesia juga menolak kaum penyuka sesama jenis.

Penolakan yang dialami oleh kaum homoseksual membuat kaum tersebut menggunakan media sosial untuk membangun identitas diri. Media sosial membantu kaum homoseksual untuk terbuka terhadap khalayak umum, bersosialisasi dengan sesama manusia terutama kaum sesama jenis, mendapatkan pasangan, hingga mencari penghasilan. Beberapa media sosial yang dikhususkan untuk kaum homoseksual yaitu Grindr, Badoo, dan Blued. Namun penelitian ini menggunakan media sosial Twitter untuk mendapatkan data dari kaum homoseksual. Data dari tweet Twitter yang merupakan text mining akan dilakukan sentimen analisis dan pengklasifikasian menggunakan metode Naïve Bayes serta dibandingkan dengan $K$-Nearest Neighbor.

Twitter merupakan salah satu media sosial dengan jutaan pengguna. Jumlah pengguna Twitter pada tahun 2016 yaitu sekitar 332 juta pengguna bulanan dengan 500 ribuan tweet setiap hari dan 200 milliaran tweet setiap tahun [5]. Twitter digunakan dalam penelitian ini karena proteksi terhadap tweet, gambar, dan video yang bersifat pornografi masih lemah sehingga bila ditelusuri secara khusus maka dapat ditemukan konten-konten pornografi dengan mudah.

Text mining adalah suatu proses penambangan data berupa teks yang dilakukan oleh komputer dimana data tersebut dapat memberikan informasi-informasi untuk dilakukan analisa keterhubungannya [6]. Sedangkan sentimen analisis adalah suatu riset yang mengelola opini-opini dari topik tertentu untuk menghasilkan nilai positif, negatif, dan netral dari topik tersebut. Adapun opini-opini tersebut didapatkan melalui penambangan data dokumen, website, atau media sosial $[6,7]$.

Beberapa penelitian sebelumnya tentang sentimen analisis diantaranya adalah penelitian pertama membahas tentang analisis sentimen pasar otomotif mobil pada tweet Twitter dengan metode Naïve Bayes dimana pada penelitian ini bertujuan untuk mengetahui merek mobil terlaris di Twitter. Hasil penelitian ini menunjukkan bahwa tingkat akurasi Naïve Bayes yaitu 93\% [6]. Penelitian kedua yaitu sentimen analisis tweet berbahasa Indonesia dengan Deep Belief Network (DBN) dan hasil DBN dibandingkan dengan Naïve Bayes dan Support Vector Machine (SVM). Tujuan penelitian tersebut adalah untuk mengetahui hasil sentimen terhadap tweet berbahasa Indonesia di Twitter dan hasil akurasi DBN sebesar 93.31\%, Naïve Bayes sebesar 79.10\%, dan SVM sebesar 92.18\% [7].

Berbeda dengan penelitian sebelumnya, tujuan dari penelitian ini adalah mengetahui hasil sentimen positif dan negatif terhadap keseluruhan data uji tweet kaum homoseksual Indonesia di Twitter dan dari hasil sentimen analisis tersebut dapat diinfokan ke publik untuk menggunakan media sosial terutama Twitter secara tepat. Selain itu juga, untuk mengetahui perbandingan tingkat akurasi antara Naïve Bayes dengan $k$-Nearest Neighbor (k-NN).

\section{METODOLOGI PENELITIAN}

\subsection{Penentuan Hashtag}

Penelitian ini dimulai dengan menganalisis dan menentukan hashtag (\#) yang sering muncul di Twitter yang berkaitan dengan homoseksual di Indonesia. Hashtag pada Twitter membantu dalam mengumpulkan data tweet sehingga data penelitian akan lebih terarah. Terdapat lima hashtag yang dipilih dalam penelitian ini yaitu \#gayindonesia, \#rtgay, \#gaybrondong, \#gaybocah, dan \#pijatgay.

\subsection{Pengumpulan Data}

Pengumpulan data dilakukan berdasarkan hashtag Twitter yang telah dipilih. Data didapat dengan mengunakan Twitter API dengan tools yang digunakan yaitu Rapidminer Studio versi 7.6.1. Data-data tersebut disimpan ke Microsoft Excel 2016 dimana setiap hashtag terdiri dari 500 data. Gambar 1 menunjukkan proses pengumpulan data menggunakan Rapidminer Studio. 


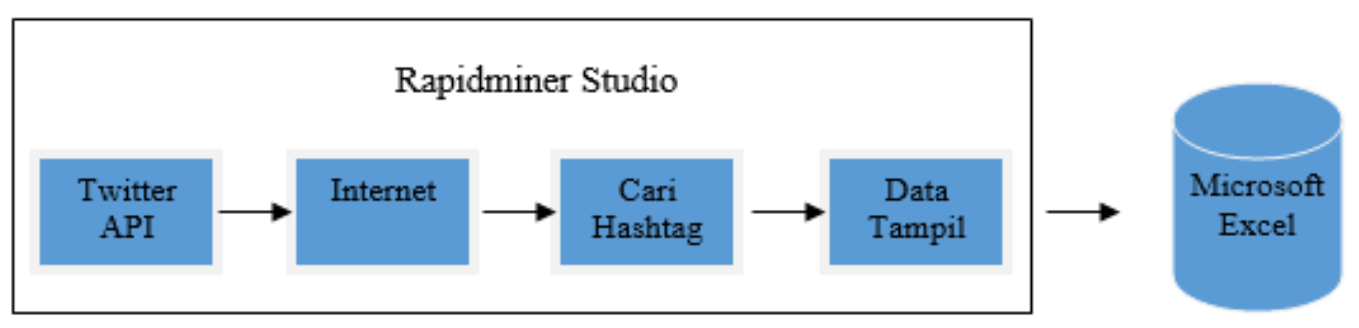

Gambar 1. Proses Pengumpulan Data

Proses pengumpulan data dimulai dari mengatur Twitter API di Rapidmaner Studio. Kemudian Twitter API dihubungkan ke internet untuk login Twitter. Langkah berikutnya adalah memasukkan hashtag dan memilih bahasa Indonesia lalu dijalankan dan data akan tampil sesuai hashtag tersebut. Data dalam Rapidmaner Studio disimpan ke Microsoft Excel untuk dilakukan proses selanjutnya. Tabel 1 menunjukkan beberapa contoh data tweet dengan hashtag \#gayindonesia

Tabel 1. Contoh Data Tweet Twitter dengan Hashtag \#gayindonesia

\begin{tabular}{|c|c|}
\hline Username & Tweet \\
\hline realsansan & $\begin{array}{l}\text { @Gaylndonesia stay di medan } 20 \text { y.o min wa } 083879937174 \text { cari buat apa aja } \\
\text { \#gayindonesia\#rtgay }\end{array}$ \\
\hline iwan & $\begin{array}{c}\text { RT @AbiRezaa: Libur panjang saatnya ngentot enak @Ony_ron @sem_fack } \\
\text { @abutomy93 @AhmadHarahap15 @nughanizm2 \#gayindonesia\#gaymedan } \\
\text { \#gayngentot \#anal \#gay... }\end{array}$ \\
\hline David Malaka & $\begin{array}{l}\text { @nyoman_satrya @TurnBackPorn2nd @SuteraJo @tindikpentil @Gaylndonesia awas } \\
\text { penyakit maaaas,jgn asal masukin doank \#gayindonesia }\end{array}$ \\
\hline Gigih Arjuna & $\begin{array}{c}\text { Mksh yg sudah BOKING SAYA di PURWOKERTOWA } 08157686707 \text { \#gayindonesia } \\
\text { \#rtsurabaya\#gaypurwokerto\#gaysmp }\end{array}$ \\
\hline Joshua & $\begin{array}{c}\text { Malam Surabaya... Malam mingguan yuuk.. \#surabaya\#gaysurabaya } \\
\text { \#gayindonesia\#gaybrondong\#gayindonesia }\end{array}$ \\
\hline
\end{tabular}

\subsection{Proses Proprocessing}

Tujuan dari preproccesing adalah untuk membersihkan data, menghilangkan tweet yang muncul berulang, dan membakukan kalimat yang tidak baku sehingga mendapatkan data bersih. Tahap preprocessing dalam penelitian ini sebagai berikut :

a. Seleksi Komentar

Data yang telah dikumpulkan pada tahap pengumpulan data ternyata ada data yang berulang dikarenakan adanya re-tweet tanpa diberikan komentar. Re-tweet merupakan salah satu fitur Twitter untuk membagikan tweet milik orang lain. Data-data yang berulang diseleksi dan dihapus untuk memaksimalkan penelitian. Hasil seleksi komentar didapatkan data-data yang akan digunakan dalam penelitian.

b. Cleaning

Cleaning merupakan proses pembersihan tiap tweet dari hal-hal yang tidak dibutuhkan dalam penelitian. Beberapa hal yang akan dilakukan proses cleaning pada penelitian ini yaitu emoticon, hashtag, username (@username),dan URL (http://www.website.com).

c. Normalisasi Kalimat

Normalisasi kalimat merupakan proses untuk mengubah data tweet yang tidak baku menjadi kalimat baku. Hal ini dilakukan karena ditemukan banyak tweet yang menggunakan kalimat tidak baku sehingga akan sulit dilakukan pengujian data. Contoh, apabila ditemukan kata "gk", "nggak", "tdk" maka akan diubah dengan kata "tidak".

d. Tokenisasi

Proses tokenisasi merupakan proses memecahkan data menggunakan spasi untuk dijadikan token-token. Proses ini merupakan proses akhir untuk mendapatkan data yang akan diolah untuk sentimen analisis. 


\subsection{Pembuatan Data Latih}

Penelitian ini membagi data-data yang telah dilakukan proses preprocessing menjadi dua bagian yaitu data latih dan data uji. Pembuatan data latih ini bertujuan sebagai pedoman dalam menentukan hasil data uji dan pada penelitian ini menggunakan 200 data data latih untuk setiap hashtag.

\subsection{Sentimen Analisis}

Sentimen analisis adalah suatu riset yang mengelola opini-opini dari topik tertentu untuk menghasilkan nilai positif, negatif, dan netral dari topik tersebut [6]. Data uji penelitian akan diujikan secara manual dan berdasarkan data latih yang telah dibuat dengan menggunakan metode Naïve Bayes. Hasil dari pengujian tersebut akan berupa $\mathrm{P}=$ sentimen postif dan $\mathrm{N}=$ sentimen negatif. Selain itu, hasil perhitungan Naïve Bayes akan dibandingkan dengan hasil perhitungan $k$-Nearest Neighbor $(\mathrm{k}-\mathrm{NN})$ untuk mengetahui tingkat keakurasian metode Naïve Bayes dalam penelitian ini.

\subsection{Metode Nä̈ve Bayes}

Metode Naïve Bayes adalah metode klasifikasi yang digunakan untuk menentukan kelompok kelas. Metode ini dapat mengelola data dalam jumlah besar dengan hasil akurasi yang tinggi. Rumus Naïve Bayes ditunjukkan dalam persamaan 1 [8].

$P\left(C_{j} \mid W_{i}\right)=\frac{P\left[C_{j}\right] \times P\left[W_{i} \mid C_{j j}\right)}{P\left(W_{i}\right)}$

Keterangan :

$P\left(C_{j} \mid W_{i}\right)=$ Posterior, adalah kemunculan peluang pada kategori $j$ tertentu ketika terdapat kemunculan kata $i$.

$P\left(C_{j}\right)=$ Prior, adalah peluang kemunculan dokumen pada kategori $j$.

$P\left(W_{i} \mid C_{j}\right)=$ Likehood atau Conditional Probability, adalah peluang sebuah kata $i$ masuk ke dalam kategori $j$.

$P\left(W_{i}\right)=$ Evidence, peluang kemunculan suatu kata.

$i=$ indeks kata yang berawal dari 1 sampai dengan kata ke-k.

$j=$ indeks kategori yang berawal dari 1 sampai dengan kategori ke-n.

\section{$2.7 \quad$ K-Nearest Neighbor $(k-N N)$}

K-NN adalah metode untuk melakukan klasifikasi terhadap objek berdasarkan data training yang menggunakan jarak terdekat atau kemiripan pada objek tertentu. K-NN bekerja pada jarak terpendek dari query distance ke data training sample untuk menentukan k-NNnya. Sebuah titik pada suatu ruang akan mencari kelas dengan klasifikasi data training sample terbanyak pada $\mathrm{k}$ buah tetangga terdekat. Dekat jauhnya tetangga dihitung berdasarkan Euclidean Distance [9]. Rumus k-NN ditunjukkan pada persamaan 2.

$d_{i}=\sum_{i=1}^{p}\left(x_{2 i}-x_{1 i}\right)^{2}$

Keterangan :

$\mathrm{x}_{1}=$ data latih

$\mathrm{x}_{2}=$ data uji

$\mathrm{i}=$ variabel data

$\mathrm{d}=$ jarak

$\mathrm{p}=$ dimensi data

\section{HASIL DAN PEMBAHASAN}

Penelitian ini bertujuan untuk mengetahui sentimen analisis dari tweet homoseksual di Twitter dan membandingkan hasil klasifikasi antara metode Naïve Bayes dan k-NN. Selain itu, hasil penelitian ini juga mengingatkan masyarakat Indonesia untuk menggunakan media sosial secara tepat, bijak, dan untuk hal-hal yang bernilai positif. 
Penelitian ini melakukan sentimen analisis dengan menguji 500 data tweet dimana setiap hashtag terdiri dari 100 data. Hasil pengujian ditunjukkan pada tabel 3.

Tabel 3. Rincian sentimen analisis

\begin{tabular}{lcc}
\hline Hashtag & $\begin{array}{c}\text { Sentimen } \\
\text { Positif }\end{array}$ & $\begin{array}{c}\text { Sentimen } \\
\text { Negatif }\end{array}$ \\
\hline \#gayindonesia & $33 \%$ & $67 \%$ \\
\#rtgay & $30 \%$ & $70 \%$ \\
\#gaybrondong & $30 \%$ & $70 \%$ \\
\#gaybocah & $31 \%$ & $69 \%$ \\
\#pijatgay & $34 \%$ & $66 \%$ \\
Total & $\mathbf{3 1 . 6 \%}$ & $\mathbf{6 8 . 4 \%}$ \\
\hline
\end{tabular}

Hasil sentimen analisis yaitu total rata-rata nilai sentimen negatif paling tinggi dibanding sentimen positif. Hal tersebut menunjukkan bahwa Twitter digunakan oleh kaum homoskesual untuk saling berinteraksi tentang hal-hal yang bernilai negatif.

Selanjutnya, hasil sentimen analisis dengan menggunakan metode Naïve Bayes dibandingkan dengan hasil pengujian k-NN untuk mengetahui tingkat akurasi. Hasil pengujian kedua metode tersebut akan ditampilkan dalam nilai akurasi, presisi, recall, dan F1-score. Tabel 4 menunjukkan hasil pengujian klasifikasi dengan Naïve Baiyes.

Tabel 4. Hasil pengujian naïve bayes

\begin{tabular}{lcccc}
\hline \multicolumn{1}{r}{ Hashtag } & Akurasi & Presisi & Recall & F1-score \\
\hline \#gayindonesia & $90.81 \%$ & $87.5 \%$ & $84.85 \%$ & $86.15 \%$ \\
\#rtgay & $84.85 \%$ & $77.78 \%$ & $70.00 \%$ & $73.68 \%$ \\
\#gaybrondong & $90.00 \%$ & $95.45 \%$ & $70.00 \%$ & $80.77 \%$ \\
\#gaybocah & $83.84 \%$ & $89.47 \%$ & $54.83 \%$ & $68.00 \%$ \\
\#pijatgay & $87.88 \%$ & $92.31 \%$ & $70.59 \%$ & $80.00 \%$ \\
Total & $\mathbf{8 7 . 4 8 \%}$ & $\mathbf{8 8 . 5 0 \%}$ & $\mathbf{7 0 . 0 5 \%}$ & $\mathbf{7 7 . 7 2 \%}$ \\
\hline
\end{tabular}

Berdasarkan tabel 4 maka diketahui bahwa hasil akurasi perhitungan klasifikasi dengan metode Naïve Bayes yaitu $87.48 \%$, presisi $88.50 \%$, recall $70.05 \%$, dan F1-score $77.72 \%$. Sedangkan hasil pengujian dengan k-NN ditunjukkan dalam tabel 5.

Tabel 5. Hasil pengujian k-NN

\begin{tabular}{lcccc}
\hline \multicolumn{1}{c}{ Hashtag } & Akurasi & Presisi & Recall & F1-score \\
\hline \#gayindonesia & $91.00 \%$ & $72.27 \%$ & $100.00 \%$ & $84.21 \%$ \\
\#rtgay & $85.00 \%$ & $51.85 \%$ & $87.50 \%$ & $62.12 \%$ \\
\#gaybrondong & $81.00 \%$ & $13.63 \%$ & $100.00 \%$ & $24.00 \%$ \\
\#gaybocah & $85.00 \%$ & $36.84 \%$ & $70.00 \%$ & $48.28 \%$ \\
\#pijatgay & $85.00 \%$ & $46.15 \%$ & $92.31 \%$ & $61.53 \%$ \\
Total & $\mathbf{8 5 . 4 0 \%}$ & $\mathbf{4 4 . 1 5 \%}$ & $\mathbf{8 9 . 9 6 \%}$ & $\mathbf{5 6 . 0 3 \%}$ \\
\hline
\end{tabular}

Berdasarkan tabel 5 maka diketahui bahwa hasil akurasi perhitungan klasifikasi dengan metode kNN yaitu $85.40 \%$, presisi $44.15 \%$, recall $89.96 \%$, dan F1-score 56.03\%. Proses selanjutnya adalah membandingkan akurasi Naïve Bayes dan k-NN. Perbandingan dilakukan dengan melihat nilai akurasi rata-rata dari kelima hashtag yang diuji coba. Hasil perbandingan yaitu nilai akurasi Naïve Bayes lebih besar $2.08 \%$ dari k-NN yang artinya bahwa dalam penelitian ini metode Naïve Bayes merupakan metode yang memiliki nilai akurasi tinggi dan cocok digunakan untuk melakukan klasifikasi.

Berdasarkan hasil sentimen analisis dan pengujian metode Naïve Bayes maka diketahui bahwa penggunaan Twitter secara bebas membuat kaum homoseksual berani tampil dan semakin membuka identitas diri kepada banyak orang. Pengamatan secara langsung ke data tweet ditemukan bahwa Twitter menjadi sarana yang baik untuk saling berkomunikasi diantaranya adalah mencari pasangan sejenis, ajakan untuk melakukan hubungan seks, saling berbagi foto-foto seks dan masturbasi, dan penawaran pijat plus (pijat dan diakhir hubungan seks). Sedangkan untuk sentimen positif menurut data ditemukan tweet bernilai positif berisi peringatan dan berita tentang penyimpangan dan penyakit menular seksual dan penjualan produk umum.

Penyebaran informasi, foto, dan video yang berkaitan dengan pornografi termasuk pornografi homoseksual dapat ditemukan dengan mudah di Twitter. Penggunaan Twitter secara luas dan bebas 
membuat Twitter menjadi media yang dapat meningkatkan pengaksesan pornografi di Indonesia. Peningkatan tersebut tentunya akan memicu terjadinya kejahatan seksual dan berbagai penyimpangan lain. Hasil penelitian ini mengingatkan kepada para pengguna Twitter untuk lebih selektif dan kritis dalam penggunaannya.

\section{KESIMPULAN}

Berdasarkan penelitian yang telah dilakukan maka didapat kesimpulan bahwa penelitian ini menggunakan lima hashtag yang berkaitan dengan pornografi homoseksual untuk mendapatkan data dari Twitter. Hasil sentimen analisis terhadap kelima hashtag tersebut menunjukkan bahwa nilai sentimen negatif sangat tinggi dengan total rata-rata adalah $68.4 \%$. Hasil sentimen tersebut dapat diartikan bahwa Twitter menjadi salah satu media berkomunikasi oleh kaum homoseksual di Indonesia. Kehadiran Twitter membantu kaum homoseksual tersebut untuk membuka diri dan saling berbagi hal-hal negatif dengan sesama kaum tersebut. Penelitian ini menggunakan metode Naïve Bayes dalam melakukan klasifikasi dan untuk mengetahui keakurasian dari metode tersebut maka dilakukan perbandingan dengan k-NN. Hasil perbandingan kedua metode tersebut berdasarkan total rata-rata pengujian kelima hashtag adalah Naïve Bayes sebesar $87.48 \%$, dan k-NN sebesar $85.40 \%$. Jadi, metode Naïve Bayes memiliki nilai akurasi lebih baik dari metode $\mathrm{k}-\mathrm{NN}$.

\section{DAFTAR PUSTAKA}

[1] Purba, D. O., 2017. “Ini Kronologi Penggerebekan Pesta Kaum Gay di Kelapa Gading”. Tersedia: http://megapolitan.kompas.com/read/2017/05/22/17453141/ini.kronologi.penggerebekan.pesta.kaum .gay.di.kelapa.gading. Diakses: 3 Oktober 2017.

[2] Ayu, R., 2017. "Penggeberekan Pesta Gay di Harmoni Bermula dari Hal ini”. Tersedia: http://www.tribunnews.com/metropolitan/2017/10/07/penggerebekan-pesta-gay-di-harmonibermula-dari-hal-ini. Diakses: 3 Oktober 2017.

[3] Priyonggo, R., 2017. “Sudah Telanjang, Pesta Seks Kaum Gay di Hotel Oval Digerebek”. Tersedia: http://beritajatim.com/gaya_hidup/296626/sudah_telanjang,_pesta_seks_kaum_gay_di_hotel_oval_d igrebek.html. Diakses: 3 Oktober 2017.

[4] Grov, C., Breslow, A. S., Newcomb, M. E., Rosenberger, J. G., and Bauermeister, J. A., 2014. "Gay and Bisexual Men's Use of the Internet: Research from the 1990s through 2013", J Sex Res.

[5] Maulana, A., 2017. “Twitter Rahasiakan Jumlah Pengguna di Indonesia”. Tersedia: https://www.cnnindonesia.com/teknologi/20160322085045-185-118939/twitter-rahasiakan-jumlahpengguna-di-indonesia/. Diakses: 10 November 2017.

[6] Rustiana, D., and Rahayu, N., 2017. "Analisa Sentimen Pasar Otomotif Mobil: Tweet Twitter menggunakan Naïve Bayes", Jurnal Simetris 8. 1, 113-120.

[7] Zulfa, I., and Winarko, E., 2017. "Sentimen Analisis Tweet Berbahasa Indonesia dengan Deef Belief Network", IJCSS 11. 2, 187-198.

[8] Lestari, A. R. T., Perdana, R. S., and Fauzi, M. A., 2017. “Analisa Sentimen Tentang Opini Pilkada DKI 2017 Pada Dokumen Twitter Berbahasa Indoensia Menggunakan Naïve Bayes dan Pembobotan Emoji”, Jurnal Pengembangan Teknologi Informasi dan Ilmu Komputer 1. 12, 17181724.

[9] Riany, J., Fajar, M., and Lukman, M. P., 2016. "Penerapan Deep Sentiment Analysis pada Angket Penilaian Terbuka Menggunakan K-Nearest Neighbor", Jurnal Sisfo 6. 1, 147-156.

[10] Ling, J., Kencana, I. P. E., and Oka, T. B., 2014. "Analisis Sentimen Menggunakan Metode Naïve Bayes Classifier dengan Seleksi Fitur Chi Square”, E-Jurnal Matematika 3. 